\title{
EXCESS SENSITIVITY OF PRE-LEUKAEMICS TO PNEUMONIA \\ A MODEL SITUATION FOR STUDYING THE INTERACTION OF INFECTIOUS DISEASE WITH CANCER
}

\author{
G. W. KNEALE \\ Department of Social Medicine, Oxford University, 8 Keble Road, Oxford
}

\section{INTRODUCTION}

\section{The Hypothesis AND its PRedictions}

A short time ago it was suggested by Stewart and Kneale (1969) that intervals between the start of a cancer process (initiation date) and the onset of symptoms (onset date) were approximately constant, characteristic of the type of cancer and measured in years and that during these hidden survival times or latent periods normal stem cells were being replaced by cancer stem cells. Reserves of normal tissue are normally so plentiful that this early effect of the cancer process was considered to be unlikely to cause trouble unless the reticuloendothelial system was involved. But should this happen, a progressive loss of normal stem cells might lead to a situation in which the individuals concerned appeared to be well but were in fact unable to cope with infections because of the acquired immunological incompetence. The following consequences of this hypothetical situation were predicted:

(1) The medical histories of children with leukaemia should show a higher than average incidence of minor infections with complications such as pneumonia during the years immediately preceding recognition of the malignant disease.

(2) For some children the level of immunological incompetence induced by a shortage of normal leucocyte precursors might be such that a fulminating infection could cause death before the underlying malignancy was recognized. Even if this situation were common it would be impossible to detect it from the medical histories of children who survived the infection to develop overt leukaemia, but it should be possible to establish a negative correlation between infection deaths and leukaemia deaths because when the infection rate was high many children incubating leukaemia would die in this way and so the number of overt leukaemia deaths would be lowered.

(3) Due to the assumption of an approximately constant latent period the above effects should apply with greater force to older children than to the children who are due to develop leukaemia in the first few years of life after spending part of the latent period in utero.

To test these predictions two illustrations have been chosen. In the first it is possible for a child to recover from an attack of pneumonia or bronchitis and subsequently to be ascertained as either (1) a leukaemic death; (2) a solid tumour death; or (3) a healthy control. In the second illustration one only knows how many children died of pneumonia or leukaemia each year in a defined area at a given age and what the corresponding population size was.

\section{The Measure of Infection Sensitivity}

For each illustration the measure taken of the infection sensitivity of children incubating leukaemia (pre-leukaemics) has been the excess risk of contracting pneumonia $(E)$ relative to the normal risk and is defined by the equation:

$$
E=\frac{Q}{P} \times\left(\frac{1-P}{1-Q}\right)-1
$$

where $P$ is the normal risk of pneumonia infection expressed as an age-specific proportion with history of pneumonia (first illustration) or as an age-specific death rate (second illustration), and $Q$ is the corresponding rate for pre-leukaemics.*

*The reason why this expression for $E$, implying as it does that the risks are additive on a logit scale rather than on a logarithmic scale (Cox, 1970), has been chosen rather than the simpler definition:

$$
E=Q / P-1
$$

based on ordinary relative risk, is as follows:

In the first illustration, where $P$ and $Q$ are both directly observable, both definitions of $E$ give equally reasonable results; however, in the second illustration $O$ is not directly observable, and in order to estimate $E$, it is necessary to use the following method:

One assumes that the aetiological relationships between pneumonia and leukaemia are such that $E$, for children due to develop leukaemia at a given age and for pneumonia attacks at a given interval before expected death from leukaemia is truly constant and does not vary expected death from leukaemia, is truly constant and does not vary with birth cohort (as $P$ and $Q$ do). With this assumption it is possible to estimate $E$ for any definition of it, as will be shown for equation 1 (see p. 154). However, this method has the defect that, for some definitions of $E$, there is no necessity that the values of $Q$ obtained by back substitution in the equation defining $E$ be reasonable, i.e., they may lie outside the range $0-100 \%$.

It may be shown that if the true value of $E$, however defined, is very large, the values of $Q$ estimated using methods based on equation 2 may well be greater than $100 \%$ and that only definitions of $E$ which 2 may well be greater than $100 \%$, and that only definitions of $E$ which approximate equation 1 for large values of $P$ and $Q$ avoid this diffi-
culty. It may also be shown that in order to avoid the similar difficulty 
TABLE I

CLASSIFICATION OF 3,879 CANCERS BY TYPE, AGE AT DEATH, AND INTERVAL (YEARS) BETWEEN MOST RECENT ATTACK OF PNEUMONIA OR BRONCHITIS BEFORE DIAGNOSIS AND DEATH, AND CORRESPONDING CLASSIFICATION FOR 3,879 CONTROLS

\begin{tabular}{|c|c|c|c|c|c|c|c|c|c|}
\hline \multirow[b]{2}{*}{ Type } & \multirow{2}{*}{$\begin{array}{l}\text { Age at Death or } \\
\text { Corresponding Age } \\
\text { for Controls (yr) }\end{array}$} & \multicolumn{8}{|c|}{ Interval between Attack and Death } \\
\hline & & $\begin{array}{c}\text { No } \\
\text { Attack }\end{array}$ & $\begin{array}{l}\text { Same } \\
\text { Year }\end{array}$ & 1 & 2 & 3 & 4 & $\begin{array}{c}\text { No Attack } \\
\text { Date } \\
\text { Recorded }\end{array}$ & Total \\
\hline \multirow[t]{2}{*}{ Leukaemias } & $\begin{array}{l}\mathbf{0} \\
1 \\
2 \\
3 \\
4\end{array}$ & $\begin{array}{l}190 \\
231 \\
359 \\
401 \\
385\end{array}$ & $\begin{array}{r}9 \\
22 \\
9 \\
9 \\
3\end{array}$ & $\begin{array}{r}-8 \\
19 \\
5 \\
2\end{array}$ & $\begin{array}{r}\overline{7} \\
12 \\
27 \\
5\end{array}$ & $\frac{7}{78}$ & $\begin{array}{l}\overline{-} \\
\overline{9}\end{array}$ & $\begin{array}{l}\mathbf{0} \\
\mathbf{3} \\
\mathbf{1} \\
\mathbf{3} \\
\mathbf{9}\end{array}$ & $\begin{array}{l}199 \\
264 \\
400 \\
453 \\
429\end{array}$ \\
\hline & Total & 1,566 & 52 & 34 & 44 & 24 & 9 & 16 & 1,745 \\
\hline \multirow[t]{2}{*}{ Solid tumours } & $\begin{array}{l}\mathbf{0} \\
\mathbf{1} \\
\mathbf{2} \\
\mathbf{3} \\
\mathbf{4}\end{array}$ & $\begin{array}{l}370 \\
407 \\
450 \\
393 \\
342\end{array}$ & $\begin{array}{r}7 \\
18 \\
5 \\
8 \\
2\end{array}$ & $\begin{array}{r}\overline{16} \\
23 \\
7 \\
2\end{array}$ & $\begin{array}{r}- \\
14 \\
19 \\
5\end{array}$ & $\overline{\bar{Z}}$ & $\bar{z}$ & $\begin{array}{l}0 \\
5 \\
5 \\
6 \\
6\end{array}$ & $\begin{array}{l}377 \\
446 \\
497 \\
438 \\
376\end{array}$ \\
\hline & Total & 1,962 & 40 & 48 & 38 & 16 & 8 & 22 & 2,134 \\
\hline \multirow[t]{2}{*}{ Controls } & $\begin{array}{l}\mathbf{0} \\
1 \\
2 \\
\mathbf{3} \\
\mathbf{4}\end{array}$ & $\begin{array}{l}563 \\
662 \\
828 \\
816 \\
747\end{array}$ & $\begin{array}{r}9 \\
20 \\
10 \\
7 \\
5\end{array}$ & $\begin{array}{r}\overline{22} \\
30 \\
8 \\
5\end{array}$ & $\begin{array}{l}\overline{7} \\
21 \\
37 \\
11\end{array}$ & $\begin{array}{l}\bar{Z} \\
\overline{17} \\
18\end{array}$ & $\begin{array}{l}\bar{Z} \\
\overline{13}\end{array}$ & $\begin{array}{l}4 \\
6 \\
8 \\
6 \\
6\end{array}$ & $\begin{array}{l}576 \\
710 \\
897 \\
891 \\
805\end{array}$ \\
\hline & Total & 3,616 & 51 & 65 & 69 & 35 & 13 & 30 & 3,879 \\
\hline
\end{tabular}

\section{PNeumonia followed by LeUKaemia}

This analysis is effectively an extension of an earlier one by Stewart, Webb, and Hewitt (1958) of data from the Oxford Survey of Childhood Cancers, which showed that a recent attack of pneumonia was recorded more often for children who subsequently died of leukaemia than for either healthy controls or children who subsequently died of a solid tumour.

This analysis is based on 7,758 children under the age of 5 years who appeared in the Oxford Survey as children with records of medical histories. Between 1952 and 19653,879 (1,745 leukaemias and 2,134 solid tumours) had died of malignant disease and 3,879 were alive and well at the time of ascertainment (controls). Table I shows the classification of the cancers by type, age at death, interval before death of the most recent attack of pneumonia or bronchitis before diagnosis of the cancer and the corresponding classification of the controls. (Note: The basis of this correspondence is that in the Oxford Survey each control is matched to one of the cancers for date of birth.)

at the other end of the range, namely, that if the true value of $E$, however defined, is very small, the estimated values of $Q$ may be less than $0 \%$, the definition of $E$ must approximate

$$
E=\exp (\sqrt{ } Q-\sqrt{ } P)-1
$$

for small values of $P$ and $Q$ But definitions which do this .... (3) readily interpretable, and so since this paper is mainly interested in larse values of $E$. large values of $E$, I have chosen to use equation 1 which gives reasonrange and is also readily interpretable. The impossible negative results for $E$ (i.e., those less than 1 , which imply a negative $Q$ ) which have arisen in Table IV in positions where the true values of $E$, however defined, are expected to be small, must in consequence be regarded as due to sampling error (none is significantly different from zero).
The proportion with a history of pneumonia for pre-leukaemics who survive the pneumonia and for ordinary children, $Q$ and $P$ respectively, may be estimated directly from the data and then the excess risk of being attacked by bronchitis or pneumonia and surviving to develop cancer may be calculated by equation 1 . The values of $E$ found are 1.31 for leukaemias and 0.43 for solid tumours for attacks less than one year before death, and for attacks more than one year before death the corresponding figures are 0.36 and 0.14 respectively. The equality of the proportions may be tested by chi-square and these tests show that the risk was significantly greater for leukaemias than for solid tumours $\left(\chi^{2}=5.48\right.$ at 1 D.F. $P<0.02)$ and greatest in the year immediately preceding death $\left(\chi^{2}=3.94\right.$ at 1 D.F. $\left.P<0.05\right)$. A more detailed analysis of the excess risk for the leukaemias by age is given in Table II. This shows that for all ages the risk is greatest in the year before death, thus prediction 1 (see Intoduction) is perfectly confirmed.

\section{Death from PNeumonia before OVERT LeUKaEMia}

\section{Avoiding Pitfalls of Correlation In}

Presence of TREND

The most straightforward method of testing prediction 2 would be to correlate leukaemia and pneumonia death rates, but one immediately runs into the danger pointed out by Yule (1926), namely that if trends are present, their effects will tend to dominate the correlation. One way of circumventing 
TABLE II

EXCESS RISK FOR A PRE-LEUKAEMIC TO BE ATTACKED BY PNEUMONIA OR BRONCHITIS AND SURVIVE TO DEVELOP OVERT LEUKAEMIA TABULATED BY AGE AT DEATH FROM LEUKAEMIA AND INTERVAL (YEARS) BETWEEN ATTACK AND DEATH

\begin{tabular}{|c|c|c|c|c|c|c|}
\hline \multirow[b]{2}{*}{ Age at Death (yr) } & \multicolumn{6}{|c|}{ Interval between Attack and Death } \\
\hline & Same Year & 1 & 2 & 3 & 4 & $\begin{array}{l}\text { No Attack Date } \\
\text { Recorded }\end{array}$ \\
\hline $\begin{array}{l}0 \\
1 \\
2 \\
3 \\
4\end{array}$ & $\begin{array}{l}1.96 \\
2.14 \\
1.04 \\
1.56 \\
0.13\end{array}$ & $\begin{array}{r}-0.02 \\
0.44 \\
0.23 \\
-0.25\end{array}$ & $\begin{array}{r}\overline{-} \\
0.29 \\
0.46 \\
-0.15\end{array}$ & $\begin{array}{c}\overline{ } \\
\overline{-0.08} \\
0.70\end{array}$ & $\begin{array}{l}\overline{ } \\
\overline{0.31}\end{array}$ & $\begin{array}{r}1.00 \\
0.35 \\
-0.72 \\
-0.02 \\
1.85\end{array}$ \\
\hline All ages & $1 \cdot 31$ & 0.17 & 0.43 & 0.53 & 0.54 & 0.19 \\
\hline
\end{tabular}

this difficulty is to take advantage of the fact that pneumonia is an epidemic disease, and so its rate will contain short-term fluctuations which should in theory be reflected in the leukaemia rate. If, therefore, the effects of the long-term or secular trend can be removed, the remaining correlation will provide the test required. A possible method would be to remove the trend by the method of moving averages, but this is not entirely satisfactory because of the periodicities introduced by the Slutzky-Yule offect (Kendall and Stuart, 1966).

A non-parametric test was described by Stewart and Kneale (1969). This consists in dividing the whole period over which the death rates are known into short periods, say quinquennia, and taking the average of Spearman's rank correlation coefficient in each quinquennium.

A parametric method suitable for estimating the actual risks involved is as follows:

Let the initiation rate of pre-leukaemics at a certain age be $I$, the death rate from leukaemia in the same cohort at an age greater by the mean latent period be $L$, and $P$ and $Q$ the pneumonia death rates at an intermediate age for average and pre-leukaemic children respectively (see Introduction). Between the age of initiation and the age of expected death from leukaemia the cohort of pre-leukaemics will have been depleted by pneumonia by a factor (1-Q); but simultaneously the total birth cohort, relative to which $L$ is measured, will have been differentially depleted by a factor $(1-P)$. Thus the effect on the observed leukaemia death rate, assuming other causes of death are similar in both groups, is given by the relation:

$$
L=\left(\frac{1-Q}{1-P}\right) \times I
$$

By substituting from the expression for $E$ (equation 1) one gets:

$$
L=\frac{I}{(1+E P)}
$$

By taking natural logarithms and expanding one has approximately:

$\ln (L)=\ln (I)-\ln (1+E \bar{P})-[E /(1+E \bar{P})](P-\bar{P}) \stackrel{\text { N }}{\ldots}$

in which $L, I$, and $P$ vary from year to year and $\bar{P}$ is $\vec{G}$ the mean pneumonia rate. Now the trend in $\ln (I) \mathrm{N}$ may be supposed to be a low order polynomial in time and the variations about it uncorrelated with $P, \overrightarrow{ }$ so the regression coefficient $(B)$ of $\ln (L)$ on $P$ in the multiple regression on $P$ and low order powers of $\frac{C}{\omega}$ time is given by:

$$
B=-E /(1+E \bar{P})
$$

hence the excess risk for pre-leukaemics to die pneumonia before developing overt leukaemia m be estimated as:

$$
E=-B /(1+B \bar{P})
$$

and its significance tested by the statistical signific- $\frac{\circ}{\mathrm{D}}$ ance of $B$.

Since the pneumonia death rates at different ages $\overline{\overrightarrow{0}}$ in the same cohort will almost certainly be correl- $\frac{3}{5}$ ated, the above analysis is strictly speaking invalid when one wants to separate the effects of pneumonia at various intervals before expected death from $\stackrel{\varnothing}{\odot}$ leukaemia. To do this, one has by an obvious? extension of the above argument:

$$
L=I \times\left(\frac{1-Q_{0}}{1-P_{0}}\right) \times\left(\frac{1-Q_{1}}{1-P_{1}}\right) \times\left(\frac{1-Q_{2}}{1-P_{2}}\right) \times
$$

where the suffixes distinguish pneumonia rates at various intervals before expected death from $\bar{N}$ leukaemia. 0 refers to rates in the same year and 0 same age as the leukaemia death rate, 1 refers to 0 rates one year earlier and one year younger, etc. By multiple regression of $1 \mathrm{n}(L)$ on low order powers of time and $P_{0}, P_{1}$, etc., one gets corresponding regression coefficients $B_{0}, B_{1}$, etc. and estimates of $\frac{}{\Phi}$ excess risks $E_{0}, E_{1}$, etc., given by relations such as $\stackrel{\oplus}{?}$ (c.f. equation 8):

$$
E_{0}=-B_{0} /\left(1+B_{0} \bar{P}_{0}\right)
$$


$E_{0}$ will then estimate the effect of pneumonia less than one year before expected death from leukaemia, $E_{1}$ the effect between one and two years before, etc.

\section{Application to Actual Data}

The sets of data to which the above methods have been applied are the series of numbers of death registrations from pneumonia and leukaemia under the age of 5 years in (1) England and Wales from 1911 to 1962 (Registrar General); (2) the United States from 1914 to 1967 (white population only) (personal communication from Drs Moriyama and Krueger, Office of Health Statistics Analysis); and (3) Japan from 1949 to 1967 (Health and Welfare Statistics Division).

The non-parametric method was applied to pneumonia and leukaemia death rates in the same year, separately for the age groups $0-1$ and $2-4$. The results are presented in Table III and are the same

TABLE III

MEAN SPEARMAN'S RANK CORRELATION COEFFICIENTS WITHIN OUINOUENNIA BETWEEN PNEUMONIA AND LEUKAEMIA DEATH RATES TABULATED BY AGE GROUP AND COUNTRY

\begin{tabular}{|c|c|c|c|}
\hline \multirow{2}{*}{ Country } & \multicolumn{2}{|c|}{ Age Group (yr) } & \multirow{2}{*}{$\begin{array}{c}\text { Standard } \\
\text { Error }\end{array}$} \\
\hline & $0-1$ & $2-4$ & \\
\hline $\begin{array}{l}\text { England and Wales } \\
\text { U.S.A. } \\
\text { Japan }\end{array}$ & $\begin{array}{r}0 \cdot 060 \\
-0 \cdot 040 \\
0 \cdot 200\end{array}$ & $\begin{array}{l}-0.300 \\
-0.310 \\
-0.569\end{array}$ & $\begin{array}{l}0 \cdot 156 \\
0 \cdot 152 \\
0 \cdot 258\end{array}$ \\
\hline
\end{tabular}

for each set of data: a significant negative correlation in the age group 2-4 and no significant correlation in the age group $0-1$, thus confirming predictions 2 and 3 (see Introduction).

For the parametric method of estimating $E$ it proved necessary to aggregate the data in order to provide sufficiently large numbers. The method of aggregation used takes advantage of the fact that for each calendar year the pneumonia epidemics in different age groups will be correlated, whereas one really wants to study birth cohorts to estimate the risk due to pneumonia at various intervals before expected death from leukaemia. The method used for the English and Welsh data and the United States data is indicated in Fig. 1 and Table V; the method for the Japanese data was similar except that three-year age groups were used rather than two-year groups and the examination was not extended beyond the age of 3 because numbers were small.

The trends in the regression equations were represented by fifth degree polynomials for the data from England and Wales and the United States, and by third degree polynomials for the Japanese data

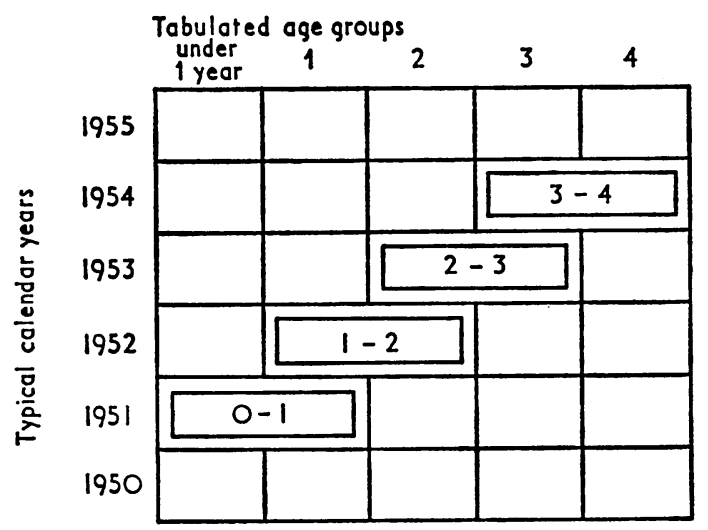

FIG. 1.-Shows the aggregation of data from published tables of deaths by calendar year and age, or the age distribution in a twoyear birth cohort at various times. Example of application: The excess risk in the age group 3-4 at two-year interval is determined by correlating the leukaemia rate in the age group 3-4 with pneumonia rate in the age group 1-2 two calendar years earlier, as described in the text.

which covers a shorter period. To show that these degrees are perfectly adequate the pneumonia rate and fitted trend in England and Wales for the age group 3-4 are shown in Fig. 2 and the corresponding leukaemia rates in Fig. 3.

The estimated values of the excess risks for a pre-leukaemic to die of pneumonia before developing overt leukaemia in various age groups and for pneumonia at various intervals before expected death from leukaemia are given in Table IV. These show that the risk is confined to ages over 2 years and to the year immediately preceding expected death from leukaemia, thus again confirming predictions 2 and 3 (see Introduction).

An example of the calculation of some of the entries in Table IV is given in Tables $V$ and VI. Table $V$ contains the raw data in terms of the agespecific death rates relevant to calculating the excess risks from pneumonia at various intervals before expected death from leukaemia, in England and Wales, age group 3-4. Table VI contains the multiple regression coefficients of $1 \mathrm{n}(L)$ on the pneumonia rates and low-order powers of time and other intermediate quantities in the calculation of the values of $E$.

When the value of $E$ is known the initiation rate of pre-leukaemics (I) can be estimated by backsubstitution in equation 5 . The trend in $I$ and the corresponding leukaemia trend for the age group 3-4 in England and Wales are shown in Fig. 4. This shows that in the early decades of the century the overt leukaemia rate was nearly halved by the effects of pneumonia, and that the virtual elimination of pneumonia deaths in later years accounts for about one-fifth of the rise in the leukaemia rate. 


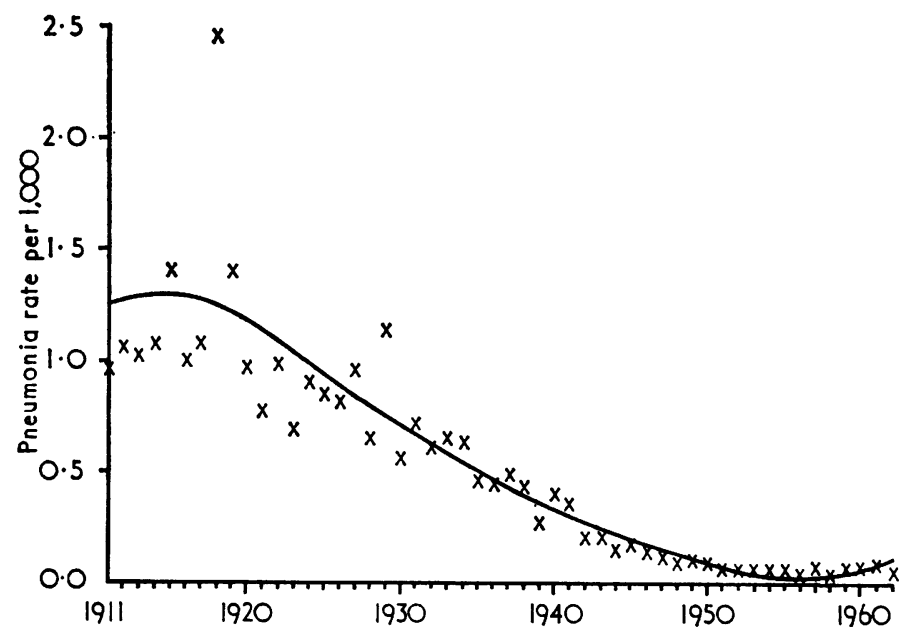

FIG. 2.-The pneumonia death rate per 1,000 and $G$ the fitted trend by fifth degree polynomial in $\omega$ England and Wales, age group 3-4.

Fig. 3.-The leukaemia death rate per 100,000 and the fitted trend by fifth degree polynomial in England and Wales, age group 3-4.

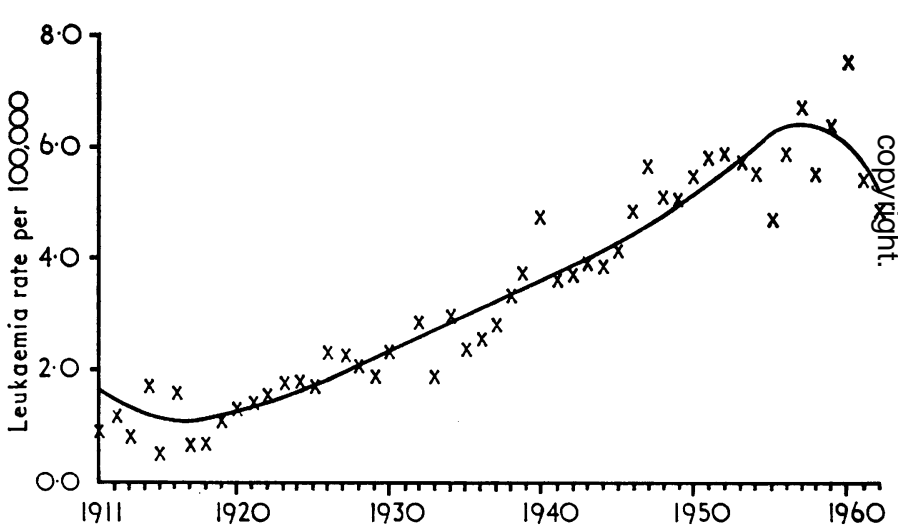

TABLE IV

EXCESS RISK FOR A PRE-LEUKAEMIC TO DIE FROM PNEUMONIA BEFORE DEVELOPING OVERT LEUKAEMIA TABULATED BY COUNTRY, AGE GROUP OF EXPECTED DEATH FROM LEUKAEMIA AND INTERVAL BETWEEN ACTUAL DEATH FROM PNEUMONIA AND EXPECTED DEATH FROM LEUKAEMIA

\begin{tabular}{|c|c|c|c|c|c|}
\hline \multirow{2}{*}{ Country } & \multirow{2}{*}{ Age Group (yr) } & \multicolumn{4}{|c|}{ Interval between Actual and Expected Deaths } \\
\hline & & Same Year & 1 & 2 & 3 \\
\hline England and Wales & $\begin{array}{l}0-1 \\
1-2 \\
2-3 \\
3-4\end{array}$ & $\begin{array}{l}83 \\
138 * \\
413 * \\
481^{*}\end{array}$ & $\begin{array}{l}\overline{-51} \\
-22 \\
-12\end{array}$ & $\begin{array}{c}\overline{\overline{2}} \\
-28 \\
30\end{array}$ & $\overline{\overline{-11}}$ \\
\hline U.S.A. & $\begin{array}{l}0-1 \\
1-2 \\
2-3 \\
3-4\end{array}$ & $\begin{array}{c}-24 \\
31 \\
186 * \\
193^{*}\end{array}$ & $\begin{array}{r}\overline{38} \\
-41 \\
-81\end{array}$ & $\begin{array}{l}\overline{-} \\
-9 \\
-19\end{array}$ & $\bar{z}$ \\
\hline Japan & $\begin{array}{l}0-2 \\
1-3\end{array}$ & $\begin{array}{r}-119 \\
481\end{array}$ & $\overline{89}$ & & \\
\hline
\end{tabular}

Note: The standard errors of the tabulated values are so large (the smallest are about 50 ) that there is little evidence of any real difierence between countries. Asterisked values $(*)$ are significantly different from zero. See footnote on p. 152 for explanation of negative values. 
Conclusions, Discussion, AND Possibilities

Thus there are four independent sets of data in support of the theory that leukaemia increases the sensitivity to pneumonia long before it is a diagnosable disease: (1) the experience of British children who died of leukaemia between 1952 and 1965; (2) the death rates of English and Welsh children from pneumonia and leukaemia between 1911 and 1962 ; (3) similar data from the United States between 1914 and 1967; and (4) similar data from Japan between 1949 and 1967.

The fact that the excess risk of developing pneu- monia and surviving is much less than the corresponding risk of developing pneumonia and dying as a result may be easily explained by realizing that in the second situation the separate risks of developing overt pneumonia as a result of infection and of dying as a result of overt pneumonia are bound to have cumulative effects, i.e., the pre-leukaemic child is both more likely to catch pneumonia and more likely to die from it; while in the first situation they will have opposing effects, i.e., the pre-leukaemic child's increased risk of death from pneumonia masks the increased risk of infection.

TABLE V

AGE-SPECIFIC LEUKAEMIA AND PNEUMONIA DEATH RATES FOR CALCULATING EXCESS RISKS FROM PNEUMONIA FOR PRE-LEUKAEMICS EXPECTED TO DIB FROM LEUKAEMIA IN AGE GROUP 3-4 IN ENGLAND AND WALES

\begin{tabular}{|c|c|c|c|c|c|}
\hline \multirow[b]{2}{*}{ Year } & \multirow{2}{*}{$\begin{array}{l}\text { Leukaemia Death } \\
\text { Rate per } 100,000 \\
\text { Age Group 3-4 }\end{array}$} & \multicolumn{4}{|c|}{ Pneumonia Death Rate per 10,000 (years earlier) } \\
\hline & & $\begin{array}{c}\text { Same Year } \\
\text { Age 3-4 }\left(=P_{0}\right)\end{array}$ & Age $2-3\left(=P_{1}\right)$ & Age $1-2^{2}\left(=P_{2}\right)$ & Age $0-1\left(=P_{8}\right)$ \\
\hline $\begin{array}{l}1914 \\
1915 \\
1916 \\
1917 \\
1918 \\
1919\end{array}$ & $\begin{array}{l}1.494 \\
0.543 \\
1.421 \\
0.673 \\
0.674 \\
0.994\end{array}$ & $\begin{array}{l}10.75 \\
13.85 \\
10.05 \\
10.69 \\
24.62 \\
13.79\end{array}$ & $\begin{array}{l}17 \cdot 81 \\
19.62 \\
26 \cdot 05 \\
18 \cdot 23 \\
20.98 \\
40.99\end{array}$ & $\begin{array}{l}49 \cdot 12 \\
48 \cdot 25 \\
52 \cdot 42 \\
66 \cdot 01 \\
44 \cdot 19 \\
50 \cdot 61\end{array}$ & $\begin{array}{c}95.06 \\
92.34 \\
97.22 \\
97.08 \\
114.5 \\
84.48\end{array}$ \\
\hline $\begin{array}{l}1920 \\
1921 \\
1922 \\
1923 \\
1924 \\
1925 \\
1926 \\
1927 \\
1928 \\
1929\end{array}$ & $\begin{array}{l}1.079 \\
1.183 \\
1.369 \\
1.704 \\
1.742 \\
1.693 \\
2.335 \\
2.235 \\
2.142 \\
1.955\end{array}$ & $\begin{array}{r}9.969 \\
7.658 \\
9.863 \\
6.815 \\
8.781 \\
8.253 \\
8.033 \\
9.411 \\
6.305 \\
11.25\end{array}$ & $\begin{array}{l}24 \cdot 23 \\
17 \cdot 40 \\
16 \cdot 63 \\
23 \cdot 11 \\
12.98 \\
17.90 \\
15 \cdot 98 \\
15 \cdot 42 \\
19 \cdot 54 \\
12 \cdot 55\end{array}$ & $\begin{array}{l}80 \cdot 24 \\
51 \cdot 52 \\
50 \cdot 11 \\
42 \cdot 38 \\
54 \cdot 94 \\
36 \cdot 36 \\
50 \cdot 49 \\
44 \cdot 53 \\
41 \cdot 19 \\
50 \cdot 22\end{array}$ & $\begin{array}{c}92.96 \\
120.0 \\
99.62 \\
96.63 \\
75.81 \\
100.6 \\
73.38 \\
104.9 \\
89.86 \\
83.71\end{array}$ \\
\hline $\begin{array}{l}1930 \\
1931 \\
1932 \\
1933 \\
1934 \\
1935 \\
1936 \\
1937 \\
1938 \\
1939\end{array}$ & $\begin{array}{l}2.331 \\
2.494 \\
2.864 \\
1.934 \\
2.959 \\
2.399 \\
2.569 \\
2.831 \\
3.388 \\
3.684\end{array}$ & $\begin{array}{l}5 \cdot 635 \\
6 \cdot 983 \\
5 \cdot 981 \\
6 \cdot 232 \\
6 \cdot 086 \\
4 \cdot 439 \\
4 \cdot 438 \\
4.639 \\
4 \cdot 148 \\
2.642\end{array}$ & $\begin{array}{c}22.38 \\
9.901 \\
13.65 \\
10.56 \\
11.47 \\
10.17 \\
7.922 \\
8.186 \\
8.558 \\
7 \cdot 188\end{array}$ & $\begin{array}{l}33 \cdot 16 \\
61 \cdot 23 \\
26 \cdot 21 \\
37 \cdot 68 \\
28 \cdot 49 \\
29 \cdot 97 \\
26 \cdot 16 \\
20 \cdot 90 \\
21 \cdot 97 \\
23 \cdot 14\end{array}$ & $\begin{array}{c}96.55 \\
68.31 \\
114 \cdot 8 \\
62.06 \\
88.62 \\
71.79 \\
70.39 \\
63.67 \\
60.54 \\
63.26\end{array}$ \\
\hline $\begin{array}{l}1940 \\
1941 \\
1942 \\
1943 \\
1944 \\
1945 \\
1946 \\
1947 \\
1948 \\
1949\end{array}$ & $\begin{array}{l}4.964 \\
3.581 \\
3.704 \\
3.920 \\
3.895 \\
4.193 \\
4.868 \\
5.645 \\
5.097 \\
5.045\end{array}$ & $\begin{array}{l}3.818 \\
3.555 \\
2.119 \\
2.274 \\
1.486 \\
1.695 \\
1.345 \\
1.106 \\
0.712 \\
0.994\end{array}$ & $\begin{array}{l}4 \cdot 611 \\
6 \cdot 947 \\
6 \cdot 248 \\
3 \cdot 838 \\
4 \cdot 099 \\
2 \cdot 782 \\
2 \cdot 570 \\
2 \cdot 202 \\
2 \cdot 321 \\
1 \cdot 509\end{array}$ & $\begin{array}{c}18.51 \\
11.86 \\
18.67 \\
16.36 \\
10.24 \\
10.33 \\
7.412 \\
6.409 \\
5.326 \\
5.967\end{array}$ & $\begin{array}{l}65 \cdot 84 \\
55 \cdot 66 \\
46 \cdot 50 \\
65 \cdot 27 \\
67 \cdot 38 \\
48 \cdot 56 \\
52 \cdot 99 \\
43 \cdot 50 \\
44 \cdot 39 \\
41 \cdot 28\end{array}$ \\
\hline $\begin{array}{l}1950 \\
1951 \\
1952 \\
1953 \\
1954 \\
1955 \\
1956 \\
1957 \\
1958 \\
1959\end{array}$ & $\begin{array}{l}5 \cdot 381 \\
5.821 \\
5 \cdot 898 \\
5.698 \\
5.494 \\
4.740 \\
5.837 \\
6.616 \\
5.457 \\
6.336\end{array}$ & $\begin{array}{l}0.794 \\
0.643 \\
0.583 \\
0.655 \\
0.609 \\
0.528 \\
0.484 \\
0.700 \\
0.423 \\
0.649\end{array}$ & $\begin{array}{l}1.591 \\
1.240 \\
1.148 \\
1.065 \\
1.263 \\
0.969 \\
0.912 \\
0.804 \\
1.048 \\
1.044\end{array}$ & $\begin{array}{l}4 \cdot 318 \\
3 \cdot 739 \\
3 \cdot 360 \\
3 \cdot 171 \\
2 \cdot 697 \\
2 \cdot 771 \\
2 \cdot 093 \\
2 \cdot 133 \\
1 \cdot 928 \\
2 \cdot 240\end{array}$ & $\begin{array}{l}43 \cdot 48 \\
29 \cdot 62 \\
28 \cdot 17 \\
19 \cdot 71 \\
20 \cdot 91 \\
17 \cdot 30 \\
17 \cdot 52 \\
13 \cdot 73 \\
13 \cdot 22 \\
12 \cdot 67\end{array}$ \\
\hline $\begin{array}{l}1960 \\
1961 \\
1962\end{array}$ & $\begin{array}{l}7 \cdot 522 \\
5 \cdot 413 \\
4 \cdot 966\end{array}$ & $\begin{array}{l}0.664 \\
0.698 \\
0.545\end{array}$ & $\begin{array}{l}1.002 \\
0.975 \\
0.974\end{array}$ & $\begin{array}{l}2 \cdot 344 \\
2 \cdot 112 \\
1 \cdot 988\end{array}$ & $\begin{array}{l}12 \cdot 68 \\
11 \cdot 85 \\
11 \cdot 65\end{array}$ \\
\hline Mean & 3.480 & $5 \cdot 069$ & $9 \cdot 808$ & $25 \cdot 87$ & 62.49 \\
\hline
\end{tabular}


The estimated period for which pre-leukaemics remain free of the effects of pneumonia by virtue of being in utero for part of their latent period (see Introduction, prediction 3) is about two years, as may be seen from Table IV, and this agrees very well with the latent period of leukaemia estimated from the age distribution of the cases induced by prenatal radiography, two-thirds of which presented in the age group 2-4 (Stewart and Kneale, 1970).

The facts noted by Hewitt (1955) that over the years the leukaemia rate has increased faster than the solid tumour rate and that this extra rate of increase for leukaemia was greatest in the age group

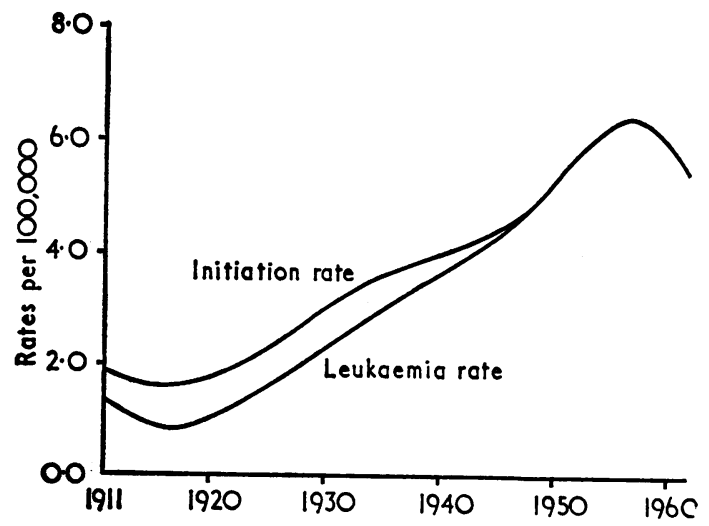

Fig. 4.-The trends in the leukaemia death rate and the corresponding initiation rate of pre-leukaemics, both per 100,000 in England and Wales, age group $3-4$.
2-4 can now easily be explained on the basis of the् virtual elimination of pneumonia and similas diseases as rival causes of death.

In this paper it has been shown that pre-leukae mics are sensitive to pneumonia, but it is almost? certain that this sensitivity will be related to the histological type. It follows that in the early year호․ of the century, when nearly half the pre-leukaemics were dying of pneumonia, the proportions of $\operatorname{dif} \mathbb{Q}$ ferent histological types found in the actuallyes diagnosed leukaemias were probably widely different from the proportions found today when most preleukaemics survive to be diagnosed as leukaemias $\overrightarrow{\vec{\omega}}$ In this way it is possible that the infectious diseases endemic in a given area at a given time determine by similar selective interactions, not necessarily alP fatal, the histological types of the haemopoieticer neoplasms found. An example of this might bej Burkitt's lymphoma which is believed to be associer ated with malaria (Lancet, 1970).

\section{SUMmary}

Starting from the hypothesis that the period from initiation to diagnosis of haemopoietic neoplasms? may be measured in years and that during these latent periods the individuals concerned may hayes lowered immunological competences, three predic:tions are made concerning possible findings. Fotro independent sets of data are presented that bear ous these predictions in the case of leukaemia anch pneumonia. From these results it may be concludeop

TABLE VI

MULTIPLE REGRESSION COEFFICIENTS AND OTHER QUANTITIES NEEDED FOR CALCULATING EXCESS RISKS FROM PNEUMONIA FOR PRE-LEUKAEMICS EXPECTED TO DIE FROM LEUKAEMIA IN AGE GROUP 3-4 IN ENGLAND AND WALES

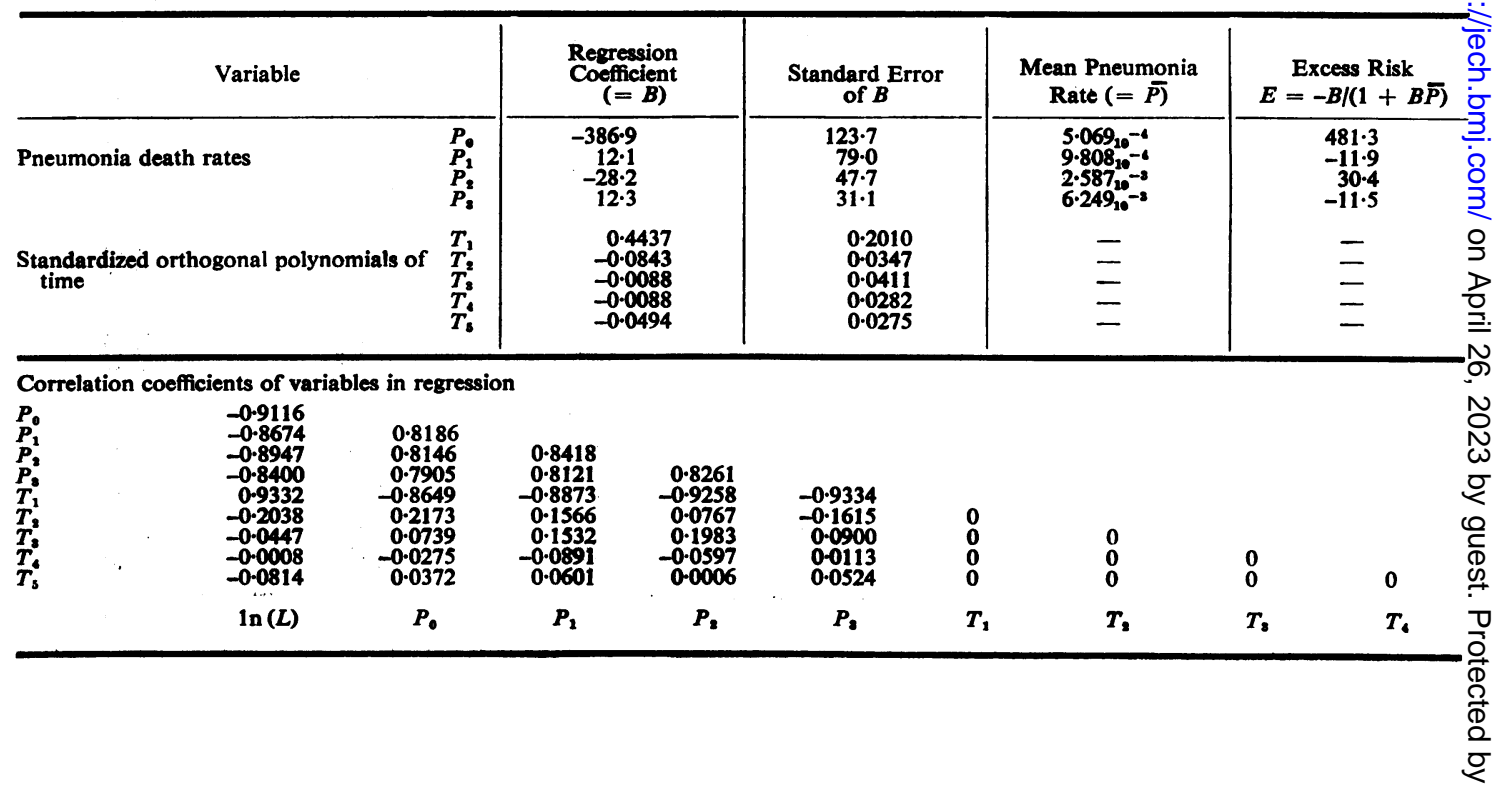


that the sensitivity of pre-leukaemics to pneumonia is greatest in the year immediately preceding expected death from leukaemia, and that then the excess risk of being attacked by pneumonia or bronchitis and surviving to develop overt leukaemia is about $1 \cdot 3$, while the corresponding excess risk of dying of pneumonia before developing overt leukaemia is about 400 . It may also be concluded that changes in the pneumonia death rate have exerted strong influences on the observed leukaemia rate.

The Oxford Survey of Childhood Cancers is supported by grants from the U.S. Public Health Service (Grant No. CA-05392), the Medical Research Council (Grant No. G.964/230/C), and the British Empire Cancer Campaign for Research. The data were collected by a nation-wide network of Public Health Departments. The author wishes to thank Dr. Moriyama and Dr. Krueger for their helpful cooperation in providing the vital statistics of the United States relating to pneumonia and leukaemia.

\section{REFERENCES}

Cox, D. R. (1970). The Analysis of Binary Data. Methuen, London.
Health and Welfare Statistics Division (1949-67). Vital Statistics of Japan, vol. 2. Tokyo.

HewITT, D. (1955). Some features of leukaemia mortality. Brit. J. prev. soc. Med., 9, 81.

Kendall, M. G., and Stuart, A. (1966). The Advanced Theory of Statistics, 2nd ed., vol. 3, p. 378. Griffin, London.

LanCet, Leading Article (1970). Burkitt lymphoma and malaria. Lancet, 2, 300.

Registrar General (1911-1962). Statistical Review of England and Wales. Tables, Part 1, Medical. H.M.S.O., London.

Stewart, A., and Kneale, G. W. (1969). Role of local infections in the recognition of haemopoietic neoplasms. Nature (Lond.), 223, 741.

and - (1970). Age-distribution of cancers caused by obstetric X-rays and their relevance to cancer latent periods. Lancet, $2,4$.

- Webb, J., and Hewitt, D. (1958). A survey of childhood malignancies. Brit. med. J., 1, 1495.

YULE, G. U. (1926). Why do we sometimes get nonsensecorrelations between time-series? A study in sampling and the nature of time-series. J. roy. Statist. Soc., 89, 1 . 